\title{
Influence of Extraction Conditions on Ultrasound-Assisted Recovery of Bioactive Phenolics from Blueberry Pomace and Their Antioxidant Activity
}

\author{
Bio Sigui Bruno Bamba ${ }^{1,2,3, *}$, John Shi ${ }^{2, *}$, Carole C. Tranchant ${ }^{3, *}$ (i) , Sophia Jun Xue ${ }^{2}$, \\ Charles F. Forney ${ }^{4}$ (i) and Loong-Tak Lim ${ }^{5}$ \\ 1 Department of Biochemistry and Genetics, Biological Sciences Training and Research Unit, \\ Université Peleforo Gon Coulibaly, Korhogo BP 1328, Côte d'Ivoire \\ 2 Agriculture and Agri-Food Canada, Guelph Research and Development Centre, \\ Guelph, ON N1G 5C9, Canada; jun.xue@agr.gc.ca \\ 3 School of Food Science, Nutrition and Family Studies, Université de Moncton, \\ Moncton, NB E1A 3E9, Canada \\ 4 Agriculture and Agri-Food Canada, Kentville Research and Development Centre, \\ Kentville, NS B4N 1J5, Canada; charles.forney@agr.gc.ca \\ 5 Food Science Department, University of Guelph, Guelph, ON N1G 2W1, Canada; llim@uoguelph.ca \\ * Correspondence: bamba_bio@upgc.edu.ci (B.S.B.B.); john.shi@agr.gc.ca (J.S.); \\ carole.tranchant@umoncton.ca (C.C.T.); \\ Tel.: +225-07-52-53-64 (B.S.B.B.); +1-226-217-8083 (J.S.); +1-506-858-3798 (C.C.T.)
}

Received: 28 June 2018; Accepted: 9 July 2018; Published: 11 July 2018

\begin{abstract}
The increase in diet-related chronic diseases has prompted the search for health-promoting compounds and methods to ensure their quality. Blueberry pomace is a rich yet underutilized source of bioactive polyphenols. For these high-value bioactive molecules, ultrasound-assisted extraction (USAE) is an attractive and green alternative to conventional extraction techniques for improving purity and yields. This study aimed to assess the impact of USAE parameters (sonication time, solvent composition, solid/liquid ratio, $\mathrm{pH}$ and temperature) on the recovery of phenolic compounds from blueberry pomace and antioxidant activity of the extracts. Total phenolic, flavonoid and anthocyanin contents (TPC, TFC and TAC) and 2,2-diphenyl-1-picrylhydrazyl (DPPH) free radical scavenging activity were analysed. USAE in 50\% ethanol/water was the most efficient, yielding the highest, TPC (22.33 mg/g dry matter (DM)), TFC (19.41 mg/g DM), TAC (31.32 mg/g DM) and DPPH radical scavenging activity (41.79 $\mathrm{mg}$ Trolox/g DM). USAE in water showed the lowest values even at low $(1 / 40)$ solid/liquid ratio $(7.85 \mathrm{mg} / \mathrm{g}$ DM, $3.49 \mathrm{mg} / \mathrm{g} \mathrm{DM}$, and $18.96 \mathrm{mg} / \mathrm{g} \mathrm{DM}$ for TPC, TFC and TAC, respectively). Decreasing the solid/liquid ratio in water or $50 \%$ ethanol significantly increased TPC, TFC, TAC and DPPH radical scavenging. With ethanol, increasing the temperature in the range $20-40{ }^{\circ} \mathrm{C}$ decreased, TPC but increased TFC and DPPH radical scavenging activity. Anthocyanin profiles of water and ethanolic extracts were qualitatively similar, consisting of malvidin, delphinidin, petunidin and cyanidin. These findings indicate that USAE is a method of choice for extracting high-value bioactive phenolics from blueberry pomace. Selective enrichment of different phenolic fractions is possible under select extraction conditions.
\end{abstract}

Keywords: blueberry pomace; polyphenols; flavonoids; anthocyanins; antioxidant activity; ultrasound-assisted extraction; extraction parameters; green technology 


\section{Introduction}

Polyphenols are natural secondary metabolites produced by plants. They are classified into different groups as phenolic acids (derivatives of benzoic acid and cinnamic acid), flavonoids (flavonols, flavones, isoflavones, flavanones, anthocyanidins and flavanols (e.g., catechins and proanthocyanidins)), stilbenes and lignans [1]. Polyphenols are known for their strong antioxidant properties and potential health benefits, including the prevention of chronic illnesses such as cardiovascular diseases, type 2 diabetes, osteoporosis, neurodegenerative diseases and some cancers, although their protective action goes beyond the modulation of oxidative stress [2]. They are increasingly used as nutritional supplements, nutraceuticals, as well as ingredients in foods, functional foods, pharmaceutical and cosmetic products.

Berries such as blueberries (Vaccinium section Cyanococcus spp.) contain abundant phenolic compounds, including anthocyanins (derived from anthocyanidins by glycosylation), flavonols and chlorogenic acids, which are mainly found in berry skin [3-5]. Some of these compounds are pigments that impart pleasant and characteristic colours to the fruits. Berry fruits can be processed into juice, wine, jam and marmalade, among other foods. Berry processing generates large quantities of pomace, which consists of skin, seeds and some flesh [6-8]. Berry flesh contains about $10 \%$ of the total polyphenols, while the skin and seeds contain $28-35 \%$ and $60-70 \%$, respectively, which makes berry processing by-products an excellent source of polyphenols [9]. According to Struck et al. [10], processing berries into juice leaves approximately $20-30 \%$ of the fruit as pomace. Blueberry production in Canada, the second largest producer worldwide after the United States, reached 176,641 tons in 2017 [11], with some consumed fresh and some being processed. Thus, blueberry pomace from food processing results in considerable losses in polyphenols and other valuable bioactive phytochemicals (most notably, carotenoids, vitamins and dietary fiber) if these are not recovered. Extracting these compounds from the pomace for subsequent use in foods, pharmaceuticals or fine chemicals for healthcare and lifestyle applications is considered the best approach for maximal valorisation of this by-product.

With increased awareness of food additives, functional foods and sustainable food production in recent years, consumers have become more demanding in regard to food quality. This promotes a high demand for more natural and safe sources of ingredients. Fruits, vegetables and their by-products are prime sources for the recovery of natural polyphenols with multiple functionalities. Several extraction techniques are available but the conventional ones (e.g., decoction, digestion, infusion, maceration, percolation, Soxhlet extraction, hot continuous extraction and counter-current extraction) have notorious drawbacks. They tend to be laborious, time consuming, produce diluted extracts, cause degradation of some of the desired compounds, and involve large amounts of solvents which contribute to environmental pollution and greenhouse effect. The remaining solvent residues are often flammable, volatile and toxic [12-15]. For safety, environmental and economical sustainability, green or eco-friendly processes are being developed using various methods such as microwave-assisted extraction, supercritical fluid extraction, accelerated solvent extraction, enzyme-assisted extraction and ultrasound-assisted extraction (USAE) $[16,17]$. Their main advantages include shorter extraction times, reduced energy consumption, fewer negative environmental impacts, increased safety as well as enhanced innovation and competitiveness [18], all of which contribute to improving the sustainability of the value chain that supplies the extracts.

In this context, USAE is a particularly attractive method due to effective extraction, energy saving and the use of moderate temperatures, which is beneficial for heat-sensitive compounds [19]. It is thus widely used to extract bioactive compounds from plant materials [20]. The main drawback of USAE is the unavoidable use of organic solvents in some applications, yet the equipment is simpler and the overall cost is lower compared to supercritical $\mathrm{CO}_{2}$ extraction which does not use organic solvent [21]. Still, this limitation can be overcome by using ethanol as USAE solvent as it is safe to use in food systems, completely biodegradable, available in high purity form and at low price [14]. Several USAE parameters affect the quality of the extracts. Among them, sonication time, temperature, 
solvent composition, solid/solvent ratio, particle size of the raw material, matrix parameters as well as ultrasonic irradiations (power, frequency) can affect the quantity, composition and biochemical properties of the extracts $[12,19,20,22]$.

Several studies have examined the USAE of bioactive phytochemicals. The results tend to differ markedly among studies according to operating conditions. Moreover, each plant material has its own unique properties in terms of chemical composition, physical characteristics, processing, storage conditions, origin (e.g., genetics and growing environment) and provider, for instance [13], which seem to affect the outcomes of USAE. Although the extraction of berry polyphenols by USAE has been studied quite extensively, extraction parameters vary widely. There is no consensus on the optimum USAE parameters and, because of the extremely diverse nature of polyphenolics and biological matrices in which they are embedded, the extraction of these compounds cannot be easily standardized or generalized [9]. Therefore, USAE methods must be developed to be suitable for use with the plant material considered and the phenolic compounds or fractions of interest. In order to develop an extraction method well tailored for blueberry pomace, the aim of the present study was to assess the effects USAE parameters (sonication time, solid/liquid ratio, solvent composition, $\mathrm{pH}$ and extraction temperature) on the total phenolic, flavonoid and anthocyanin contents and total antioxidant activity of extracts prepared from blueberry wine pomace.

\section{Results and Discussion}

This study is the first to investigate the influence of USAE conditions on the recovery of phenolic compounds from blueberry pomace and antioxidant activity of the extracts. The parameters that were varied are sonication time, solid/liquid ratio, solvent composition (\% ethanol in water), $\mathrm{pH}$ and temperature. The corresponding extraction conditions are presented in Table 1. Five series of experiments were conducted to assess the influence of each parameter and identify suitable levels for each parameter.

Table 1. Extraction conditions for ultrasound-assisted extraction of phenolic compounds from blueberry pomace.

\begin{tabular}{|c|c|c|c|c|c|}
\hline & Solid/Liquid Ratio & Temperature $\left({ }^{\circ} \mathrm{C}\right)$ & Time (min) & $\mathrm{pH}$ & $\begin{array}{c}\text { Ethanol } \\
(\% v / v) \text { in Water }\end{array}$ \\
\hline $\begin{array}{l}\text { Runs 1-3 } \\
\text { (Figure 1) }\end{array}$ & $1 / 20$ & 40 & $30-60-90$ & 5.0 & 0 \\
\hline $\begin{array}{c}\text { Runs 4-8 } \\
\text { (Figure 2A) }\end{array}$ & $\begin{array}{c}1 / 10-(1 / 10) \times 2 \\
*-1 / 20-1 / 40\end{array}$ & 40 & 60 & 3.3 & 0 \\
\hline $\begin{array}{l}\text { Runs 9-11 } \\
\text { (Figure 2B) }\end{array}$ & $1 / 10-1 / 15-1 / 20$ & 40 & 60 & 3.3 & 50 \\
\hline $\begin{array}{l}\text { Runs 12-14 } \\
\text { (Figure 3) }\end{array}$ & $1 / 15$ & 40 & 40 & 3.3 & $10-50-90$ \\
\hline $\begin{array}{l}\text { Runs 15-17 } \\
\text { (Figure 4) }\end{array}$ & $1 / 15$ & 40 & 40 & $3.3-6.3-8.3$ & 50 \\
\hline $\begin{array}{l}\text { Runs 18-20 } \\
\text { (Figure 5) }\end{array}$ & $1 / 15$ & $20-40-60$ & 40 & 3.3 & 50 \\
\hline
\end{tabular}

* $(1 / 10) \times 2$ : two sequential extractions (1/10 for 30 min each time). All the experiments were conducted in triplicate.

\subsection{Effect of Sonication Time on the Phenolic Contents of Blueberry Pomace Water Extracts}

The effect of sonication time (from 30 to $90 \mathrm{~min}$ ) was assessed using water as the extraction solvent with a solid/liquid ratio of $1 / 20$ at $40^{\circ} \mathrm{C}$. The results are shown in Figure 1 . Overall, the water extracts of blueberry pomace contained relatively small amounts of phenolics, below $15 \mathrm{mg} / \mathrm{g}$ of dry matter (DM). Over the time range investigated, total phenolic content (TPC in gallic acid equivalents) ranged from $5.84 \pm 0.03$ to $6.31 \pm 0.15 \mathrm{mg} \mathrm{GAE} / \mathrm{g}$ DM, total flavonoid content (TFC, catechin equivalents) ranged from $2.45 \pm 0.25$ to $2.85 \pm 0.11 \mathrm{mg} \mathrm{CE} / \mathrm{g} \mathrm{DM}$, while total anthocyanin content (TAC, malvidin equivalents) ranged from $10.04 \pm 0.10$ to $14.1 \pm 0.15 \mathrm{mg} \mathrm{ME} / \mathrm{g}$ DM. Extraction duration significantly 
affected TAC, but not, TPC and TFC. TAC after extraction for 90 min was significantly higher than after 30 and $60 \mathrm{~min}$.

These relatively low concentrations can be attributed to the physicochemical properties of polyphenols. These compounds contain several nonpolar portions, including the aromatic rings, which limit their solubility and thus their extraction in a highly polar solvent such as water. The higher levels of TAC overall may be explained by greater solubility in water due to the positive charge of anthocyanins and the presence of more hydroxyl groups in these molecules. Greater solubility would enhance the mass transfer which governs the extraction process. The gradual enhancement of TAC content after $60 \mathrm{~min}$ as ultrasound-assisted extraction progressed is consistent with a two-stage extraction process.

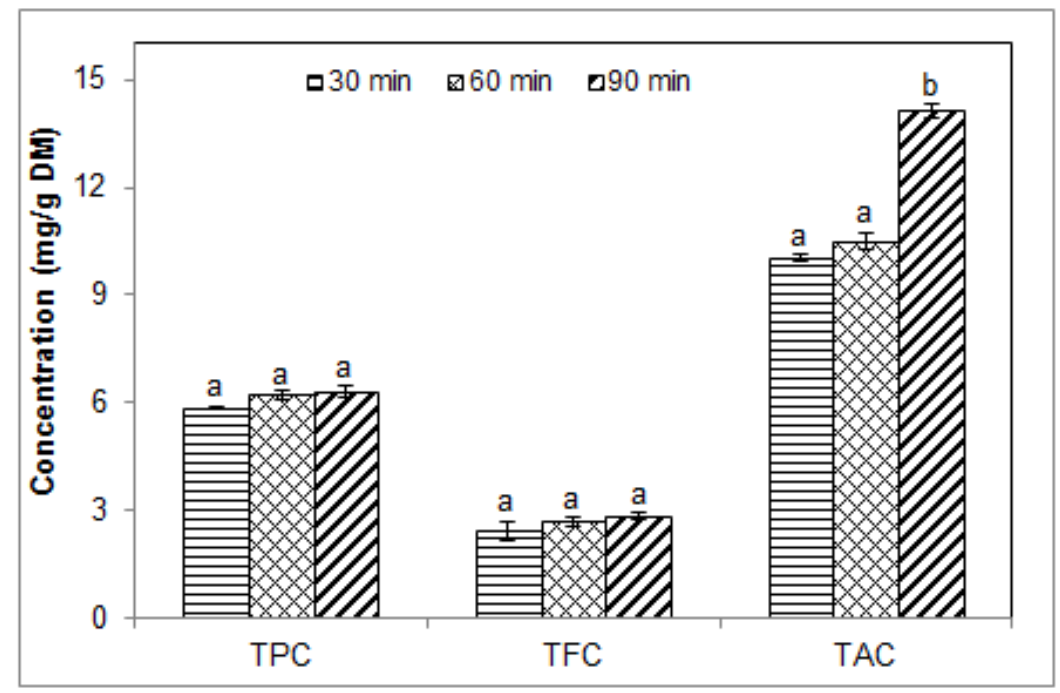

Figure 1. Effect of sonication time on the phenolic contents of blueberry pomace water extracts from ultrasound-assisted extraction at $40{ }^{\circ} \mathrm{C}$. TPC, TFC, TAC: total phenolic, flavonoid and anthocyanin contents, respectively. Means $(n=3$ replicates $) \pm$ standard deviation (SD). Different letters indicate significant effect $(p \leq 0.05)$.

Our findings are consistent with previous reports despite obvious differences in extraction conditions and plant materials. Low concentrations of, TPC and TFC (6.25 mg GAE/g and $4.04 \mathrm{mg}$ quercetin equivalents/g, respectively) were reported by Do et al. [23] using simple water extraction (without sonication) of Limnophila aromatic for $20 \mathrm{~min}$. They suggested that these low levels could be due to the ability of water to extract more nonphenolic substances such as carbohydrates, or to the formation of complexes involving phenolic compounds which may decrease their solubility in water. Wang et al. [24] found no increase in, TPC and TFC with extraction time beyond $15 \mathrm{~min}$ when extracting blueberry leaves using ultrasound-negative pressure cavitation extraction. With USAE of dried chokeberries in 50\% ethanol, Ćujić et al. [25] reported no difference between the, TPC obtained after 30 and $60 \mathrm{~min}$. TAC, however, was significantly greater after $60 \mathrm{~min}$ than after $30 \mathrm{~min}$. With maceration by simple diffusion (no sonication) in an ethanolic solvent, they found that extraction times of 30-90 min (for TPC) and 60-90 $\mathrm{min}$ (for TAC) yielded higher contents compared to shorter durations [25]. It is noteworthy that longer extraction times in water can lead to decrease in, TPC and TAC, as shown by Lapornik et al. [26] with red currant and black currant by-products (marc) extracted for 1 to $24 \mathrm{~h}$ in water without sonication. This indicates that with some plant materials, excessive extraction duration in water may cause degradation of some target compounds resulting in reduced contents. Although this was not observed in our work using USAE in water, we concluded that extraction times between 30 and $60 \mathrm{~min}$ would be a good compromise in order to avoid longer processing times. When higher TAC are desired, sonication could be extended to $90 \mathrm{~min}$. In our work, the effect of sonication time was investigated only with water. Because of this limitation, it is not certain whether 
similar effects would be observed with ethanol. Extraction times of $60 \mathrm{~min}$ and $40 \mathrm{~min}$ were used in subsequent experiments.

\subsection{Effect of Solid/Liquid Ratio on the Phenolic Contents and Antioxidant Activity of Blueberry Pomace Extracts}

The effect of solid/liquid ratio on TPC, TFC and TAC of the blueberry extracts from USAE was assessed at $40{ }^{\circ} \mathrm{C}$ using water and $50 \%$ ethanol as the extraction solvents and varying the solid/liquid ratio from $1 / 10$ to $1 / 40$ and from $1 / 10$ to $1 / 20$, respectively. Extraction duration was $60 \mathrm{~min}$. Total antioxidant activity of the ethanolic extracts was evaluated using the 2,2-diphenyl-1-picrylhydrazyl (DPPH) essay. With both solvents, TPC, TFC and TAC increased significantly with decreasing the solid/liquid ratio, as shown in Figure 2. This is consistent with the fact that lower solid/liquid ratios increase the contact surface between the plant material and the solvent, which enhances the mass transfer of soluble compounds from material to solvent [27,28]. With water (Figure 2A), TFC levels remained low, even as water quantity was multiplied by four. This may be due to low solubility of these compounds in water. The highest value of TFC was $3.49 \pm 0.19 \mathrm{mg}$ CE $/ \mathrm{g}$ $\mathrm{DM}$ at $1 / 40$. Comparison of the phenolic contents obtained at $1 / 20$ and $(1 / 10) \times 2$ shows that two sequential water extractions using a solid/water ratio of 1/10 for 30 min each time, while maintaining the total extraction time constant $(60 \mathrm{~min})$, significantly increased the extraction yield of all the phenolic fractions considered. This beneficial effect can be explained by the renewed concentration gradient between the plant material and the solvent, which occurs after renewing the extraction solvent and results in enhanced mass transfer.

With 50\% ethanol (Figure 2B)," TPC and DPPH free radical scavenging activity increased continuously with decreasing solid/liquid ratio from $1 / 10$ to $1 / 20$. The corresponding values were $22.57 \pm 0.53,24.16 \pm 0.25$ and $35.95 \pm 0.12 \mathrm{mg} \mathrm{GAE} / \mathrm{g}$ DM for, TPC and $41.39 \pm 0.61,51.75 \pm 1.21$ and $64.25 \pm 0.39 \mathrm{mg}$ TE/g DM for DPPH. This suggests that the antioxidant activity of the extracts depends on their concentration in total phenolic compounds. For TFC and TAC, a slightly different trend was observed as the increase in TFC and TAC was not continuous across all the values of solid/liquid ratio. These findings are consistent with the increased, TPC and TAC reported by Ćujić et al. [25] using maceration of chokeberries in an ethanolic solvent. In their work, the solid/liquid ratio varied from $1 / 10$ to $1 / 30$ and the increase in, TPC and TAC levelled off between $1 / 20$ and 1/30, with TAC seemingly declining at 1/30 albeit not significantly. This suggests that excessive dilution of the plant material may not lead to further enhancement of TAC under the conditions investigated. Excess of solvent, without beneficial increase in phenolic contents, should also be avoided as it leads to solvent wastage and unwarranted increase of operating costs [24]. In the present study with USAE and blueberry pomace, a ratio of $1 / 15$ in $50 \%$ ethanol was found to be a suitable compromise and was used in subsequent experiments.

Across the range of solid/liquid ratios investigated, superior concentrations of phenolic compounds were achieved in 50\% ethanol. As shown in Figure 2, TPC, TFC and TAC in the ethanolic extracts were about 5, 3 and 1.5 times greater on average, respectively, than in the water extracts. Even at the lowest solid/liquid ratio (1/40) in water, TPC, TFC and TAC remained lower than those obtained with 50\% ethanol at the highest solid/liquid ratio (1/10). Higher concentrations of, TPC and TAC in ethanol compared to water have been reported by Ćujić et al. [25] (50\% ethanol) and Lapornik et al. [26] (70\% ethanol), although their work did not involve sonication. The magnitude of the difference in phenolic contents between ethanolic and water extracts was about 1.5-2 times in the former study, which was conducted with macerated chokeberries [25], while in the latter study, it was about 2 times for macerated red and black currant residue (marc) and 5-10 times for macerated grape marc [26]. This indicates that the extent of the beneficial effect of ethanolic solvents on extraction yields varies greatly with plant material and extraction conditions. Binary solvents of ethanol and water present several advantages as ethanol can enhance the solubility of some solutes such as polyphenols, while water increases their desorption from plant matrices [29]. Differences in the structure of phenolic 
compounds affect their solubility in solvents of different polarities [30]. The addition of water to ethanol and other organic solvents generally creates a more polar medium, which facilitates the extraction of polyphenols [31].

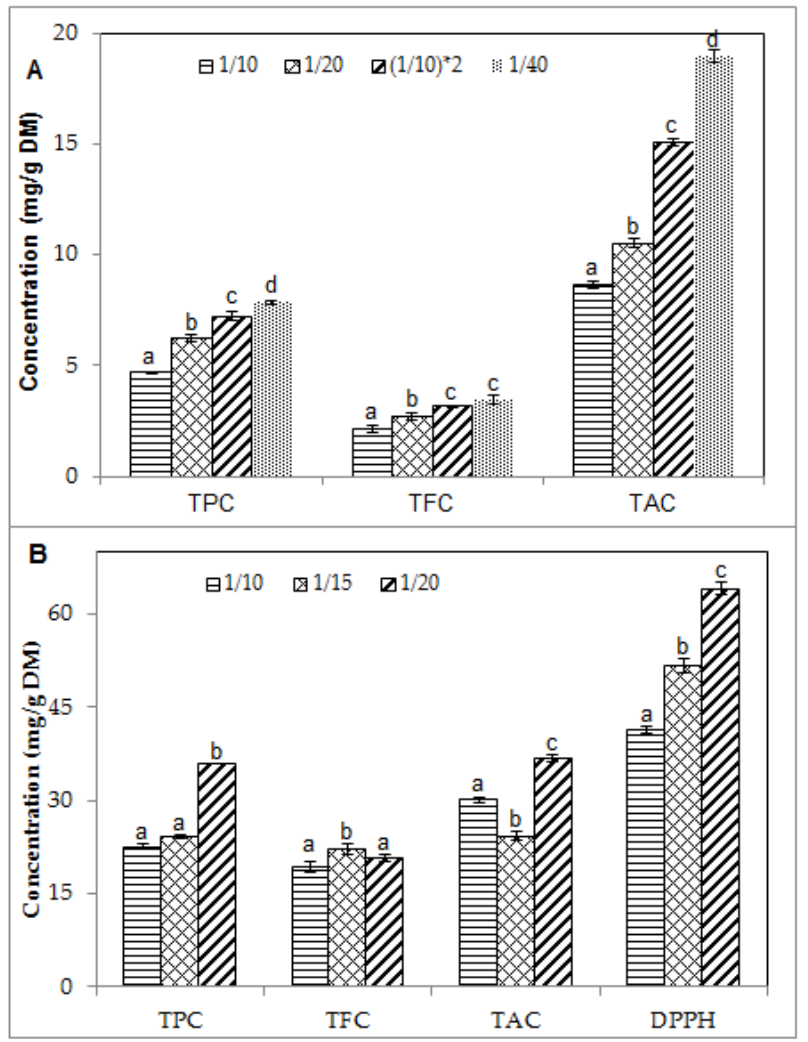

Figure 2. Effect of solid/liquid ratio on the phenolic contents and antioxidant activity of blueberry pomace (A) water extracts and (B) 50\% ethanolic extracts from ultrasound-assisted extraction $\left(40{ }^{\circ} \mathrm{C} / 60 \mathrm{~min}\right)$. TPC, TFC, TAC: total phenolic, flavonoid and anthocyanin contents, respectively; DPPH: antioxidant activity by DPPH assay. Means ( $n=3$ replicates) \pm SD. Different letters indicate significant effect $(p \leq 0.05)$.

\subsection{Effect of Ethanol Concentration on the Phenolic Contents and Antioxidant Activity of Blueberry} Pomace Extracts

To maximize the extraction of blueberry pomace phenolic compounds by USAE, ethanol concentration was varied between $10 \%$ and $90 \%$ in water. Extraction was performed at $40{ }^{\circ} \mathrm{C}$ for $40 \mathrm{~min}$ with a solid/liquid ratio of $1 / 15$ as determined in our previous sets of experiments. Ethanol was used as co-solvent as it is known to be a suitable solvent for polyphenol extraction and is recognized as safe for use in food and pharmaceutical applications intended for humans. Significantly higher TPC, TFC, TAC and DPPH free radical scavenging activity were found with $50 \%$ ethanol compared to $10 \%$ and $90 \%$ ethanol, as illustrated in Figure 3. Increasing the concentration of ethanol from $50 \%$ to $90 \%$ resulted in values that were significantly lower than those obtained with $50 \%$ and $10 \%$ ethanol, and similar to those obtained with water alone (Figure 1). Maximum and minimum values obtained with $50 \%$ vs. $90 \%$ ethanol were $22.23 \pm 0.15$ vs. $5.02 \pm 0.09 \mathrm{mg}$ GAE/g DM for TPC, $19.41 \pm 0.33$ vs. $9.71 \pm 0.19 \mathrm{mg}$ CE/g DM for TFC, and $31.32 \pm 0.73$ vs. $12.75 \pm 0.17 \mathrm{mg}$ ME/g DM for TAC, and $41.79 \pm 0.92$ vs. $10.95 \pm 0.28 \mathrm{mg}$ TE/g DM for antioxidant activity.

These findings concur with those of Ćujić et al. [25] who reported greater, TPC and TAC (18.2 mg GAE/g DM and 0.21\%, respectively) with $50 \%$ ethanol than with $70 \%$ and $96 \%$ ethanol upon the maceration of chokeberries. With $96 \%$ ethanol, these values were drastically reduced. In contrast, Dent et al. [32], also using maceration, found that an increase in the volume fraction of 
ethanol or acetone in water above $30 \%$ and up to $70 \%$ resulted in a considerable drop of extraction efficiency of total polyphenols from Salvia officinalis. Safdar et al. [29], on the other hand, reported significantly higher, TPC with $80 \%$ ethanol compared to $50 \%$ and $100 \%$ ethanol $(24,22$ and $20 \mathrm{mg}$ GAE/g, respectively) using USAE of Citrus reticulate polyphenols. At all three ethanol concentrations, TPC values in their work were similar to the value we obtained using $50 \%$ ethanol. Wang et al. [24] suggested that the range of $60-70 \%$ ethanol is the most suitable for ultrasound-negative pressure cavitation extraction of polyphenols from blueberry leaves. They found that, TPC and TFC were increased when increasing ethanol concentration from $40 \%$ to $70 \%$, while further increase of ethanol concentration up to $90 \%$ decreased the extraction yield.

These variable and sometimes conflicting reports confirm that the efficiency of polyphenol extraction in ethanolic solvents is greatly influenced by the plant material and the overall extraction conditions. Despite these variations, most studies indicate that too high or too low concentrations of ethanol in water are not conducive to the simultaneous extraction of all the phenolic compounds. Ethanol reduces the dielectric constant of the aqueous solvent, thus increasing the diffusion of molecules such as polyphenols in the solvent, but too high concentrations of ethanol could dehydrate the plant cells, which could hinder the diffusion of polyphenols from the plant material to the solvent [33]. Under the USAE conditions used in the present work with blueberries pomace, a concentration of $50 \%$ ethanol was highly effective for extracting total phenolics, flavonoids and anthocyanins. The superior antioxidant activity obtained with $50 \%$ ethanol can be attributed to the superior phenolic contents of these extracts. It cannot be ruled out that an ethanol concentration above $50 \%$, but lower than $90 \%$, could also be effective, but $50 \%$ seems a good compromise in order to keep the costs down and the extraction method as environmentally friendly as possible.

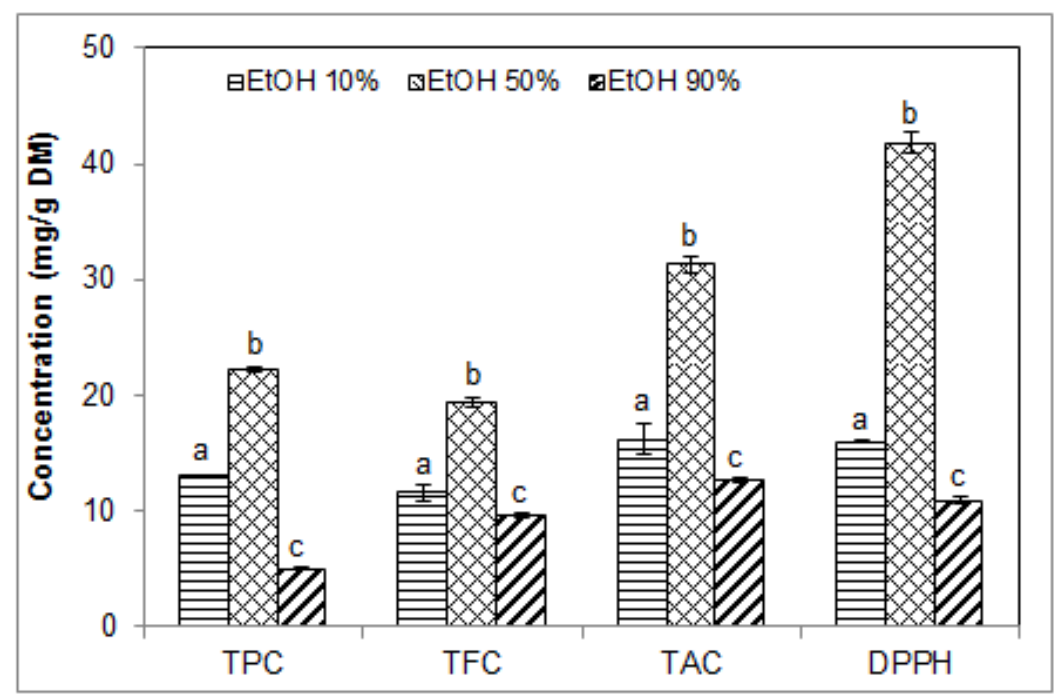

Figure 3. Effect of ethanol concentration in the extraction solvent on the phenolic contents and antioxidant activity of blueberry pomace ethanolic extracts from ultrasound-assisted extraction (40 $\left.{ }^{\circ} \mathrm{C} / 40 \mathrm{~min}\right)$. TPC, TFC, TAC: total phenolic, flavonoid and anthocyanin contents, respectively; $\mathrm{DPPH}$, antioxidant activity by DPPH assay. Means $(n=3$ replicates $) \pm \mathrm{SD}$. Different letters indicate significant effect $(p \leq 0.05)$.

\subsection{Effect of $\mathrm{pH}$ on the Phenolic Contents and Antioxidant Activity of Blueberry Pomace Extracts}

The effect of solvent $\mathrm{pH}$ (from 3.3 to 8.3 ) was assessed using $50 \%$ ethanol in water with a solid/liquid ratio of $1 / 15$. Extraction was conducted at $40{ }^{\circ} \mathrm{C}$ for $40 \mathrm{~min}$ as in the previous set of experiments., TPC and antioxidant activity were both significantly increased when the $\mathrm{pH}$ was increased above 6.3, while TAC was significantly decreased above this value (Figure 4). The corresponding values at $\mathrm{pH} 3.3$ vs. 8.3 were $22.23 \pm 0.15$ vs. $24.28 \pm 0.27 \mathrm{mg}$ GAE/g DM for TPC, 
$31.31 \pm 0.44$ vs. $29.58 \pm 0.27 \mathrm{mg}$ ME/g DM for TAC, and $41.78 \pm 0.98$ vs. $45.65 \pm 1.74 \mathrm{mg}$ TE/g DM for antioxidant activity. There was no statistically significant difference in TFC values (19.41 \pm 0.33 vs. $20.50 \pm 1.20 \mathrm{mg} \mathrm{CE} / \mathrm{g} \mathrm{DM}$ ) in the $\mathrm{pH}$ range investigated. These findings are in agreement with those shown in Figures $2 \mathrm{~B}$ and 3, which suggest that the antioxidant activity of the ethanolic extracts depends mainly on their total phenolic content.

These findings support some previous reports but discrepancies were also noted. After sonication of blueberry leaves in 50\% ethanol for $60 \mathrm{~min}$ at $\mathrm{pH} 2$ and 6, Cheng et al. [34] found lower contents of total extractable polyphenols at $\mathrm{pH} 6$ than at $\mathrm{pH} \mathrm{2,} \mathrm{which} \mathrm{seems} \mathrm{to} \mathrm{contradict} \mathrm{our} \mathrm{results} \mathrm{for}$ TPC. However, they found higher contents of non-extractable polyphenol at pH 6 [34]. At pH 6, the extractable anthocyanins were about two-fold lower than at $\mathrm{pH} 2$, which is consistent with our findings of lower TAC at $\mathrm{pH} 8.3$ compared to $\mathrm{pH}$ 3.3. Lower TAC at basic $\mathrm{pH}$ values could indicate lower extraction or some degradation of the anthocyanins under basic $\mathrm{pH}$ conditions. Our findings and previous findings such as Cheng et al.'s are difficult to compare because the $\mathrm{pH}$ ranges were different; some analytical methods and extraction conditions were also different, as were the blueberry products subject to extraction (blueberry leaves vs. pomace).

Consistent with our results for TAC, Kalt et al. [35] reported a higher concentration of monomeric anthocyanins at $\mathrm{pH} 1$, followed by $\mathrm{pH} 4$ and finally $\mathrm{pH}$ 7. These were extracted from blueberry juice. Unlike in our work, however, they found that, TPC were higher at $\mathrm{pH} 1$ than at $\mathrm{pH} 4$ and 7. They attributed the lower, TPC at $\mathrm{pH} 4$ and 7 to the irreversible loss of some anthocyanins and suggested that higher contents of polymeric anthocyanins at $\mathrm{pH} 4$ and 7 may be due to greater self-association of anthocyanin molecules at high $\mathrm{pH}$. For TAC and antioxidant activity, our findings concur with those of Librán et al. [33] who found a reduction of TAC between pH 2 and 12, and an increase in antioxidant activity between $\mathrm{pH} 2$ and $\mathrm{pH} 5,8$ and 12. For TPC, however, they found decreased contents between pH 2 and 12. They suggested that the degree of correlation between antioxidant activity and phenolic contents depends not only on TPC, but also on the composition of the extracts. They used 50\% ethanol to macerate grape wastes $(1 / 25 w / v)$ at room temperature for $2 \mathrm{~h}$ [33]. For, TPC and DPPH, our findings concur in part with those of Ruenroengklin et al. [36] who found increased, TPC between $\mathrm{pH} 2$ and 4 and increased DPPH free radical scavenging activity between $\mathrm{pH}$ 3 and 5. They also showed that, TPC started to decline at $\mathrm{pH} 5$ and 6, and that DPPH declined at $\mathrm{pH}$ 7 , which was not observed in the present study, most likely because of differences in plant materials, constitutive polyphenols and extraction conditions. Ruenroengklin et al. [36] used litchi fruit pericarp tissue macerated in 60\% ethanol., TPC and antioxidant activity from grape extracts were found to be stable during storage at $\mathrm{pH} 3$ and 5, but declined with storage time at $\mathrm{pH} 7$ and 9 [37].

Our findings and the available literature indicate that $\mathrm{pH}$ is an important parameter affecting the extractability of polyphenolic compounds. Different phenolic fractions seem to be affected differently, which can be used to selectively enrich the extracts in specific phenolic fractions. Proper adjustment of the $\mathrm{pH}$ can also help stabilizing these compounds. With USAE of blueberry pomace polyphenols, higher $\mathrm{pH}$ values in the range 6.3 to 8.3 were beneficial for enhancing, TPC and antioxidant activity, but they decreased TAC. 


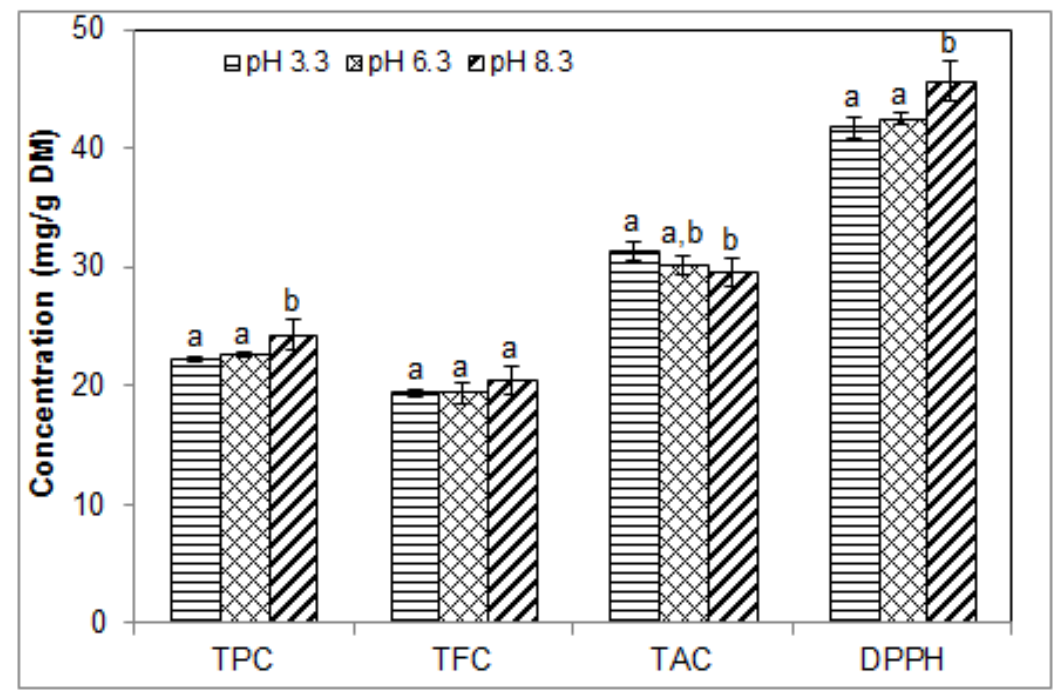

Figure 4. Effect of $\mathrm{pH}$ of the extraction solvent on the phenolic contents and antioxidant activity of blueberry pomace ethanolic extracts from ultrasound assisted-extraction (50\% ethanol, $40{ }^{\circ} \mathrm{C} / 40 \mathrm{~min}$ ). TPC, TFC, TAC: total phenolic, flavonoid and anthocyanin contents, respectively; $\mathrm{DPPH}$, antioxidant activity by DPPH assay. Means $(n=3$ replicates $) \pm \mathrm{SD}$. Different letters indicate significant effect $(p \leq 0.05)$.

\subsection{Effect of Temperature on the Phenolic Contents and Antioxidant Activity of Blueberry Pomace Extracts}

Increasing temperature generally accelerates reaction processes, including extraction and degradation. Beneficial effects of temperature during extraction processes are generally due to higher mass transfer rate, which leads to higher molecular diffusion [24], but an appropriate balance must be achieved to avoid degradation of heat-sensitive bioactives. In our study, the effect of extraction temperature was studied using $50 \%$ ethanol with a solid/solvent ratio of $1 / 15$. USAE was conducted for $40 \mathrm{~min}$ at a $\mathrm{pH}$ of 3.3 in order to stabilise the anthocyanins as determined in our previous sets of experiments. As shown in Figure 5, when temperature was increased from $20^{\circ} \mathrm{C}$ to $60{ }^{\circ} \mathrm{C}$, TPC decreased significantly from $30.33 \pm 0.27$ to $18.74 \pm 0.13 \mathrm{mg}$ GAE/g DM. Conversely, TFC increased significantly from $17.05 \pm 1.23$ to $19.38 \pm 0.86 \mathrm{mg} \mathrm{CE} / \mathrm{g}$ DM between $20^{\circ} \mathrm{C}$ and $40{ }^{\circ} \mathrm{C}$, and then to $45.45 \pm 2.46 \mathrm{mg} \mathrm{CE} / \mathrm{g} \mathrm{DM}$ at $60^{\circ} \mathrm{C}$. DPPH free radical scavenging activity also increased significantly from $35.59 \pm 0.67$ to $54.44 \pm 1.36 \mathrm{mg} \mathrm{TE} / \mathrm{g}$ DM at $20^{\circ} \mathrm{C}$ and $60^{\circ} \mathrm{C}$, respectively. Since TAC remained unchanged (30.82 \pm 0.79 to $30.12 \pm 0.60 \mathrm{mg} \mathrm{ME} / \mathrm{g} \mathrm{DM})$, increased antioxidant activity may be related to increased TFC.

Decreased, TPC at higher extraction temperature may be explained by increased solvent vapour pressure and decreased surface tension as temperature increases, which affect cavitation bubble formation and collapse during sonication. At higher temperature, higher vapour pressure causes more solvent vapours to enter the bubble cavity and more numerous cavitation bubbles, but these collapse with less intensity, thus causing less cell disruption and reducing sonication effects [20]. A contributing factor could the degradation of some phenolic compounds at $40{ }^{\circ} \mathrm{C}$ and $60{ }^{\circ} \mathrm{C}$, possibly due to hydrolysis, internal redox reactions or polymerization [32].

Although, TPC declined at higher temperatures, its value at $60^{\circ} \mathrm{C}(18.74 \pm 0.13 \mathrm{mg} \mathrm{GAE} / \mathrm{g} \mathrm{DM})$ was similar to that reported by He et al. [5] (16.01 $\pm 0.03 \mathrm{mg} \mathrm{GAE} / \mathrm{g})$ following USAE of blueberry wine pomace phenolics at $60^{\circ} \mathrm{C}$ for $35 \mathrm{~min}$ in $70 \%$ ethanol $(1 / 22$ solid/liquid ratio). In their work, TPC increased between 50-60 ${ }^{\circ} \mathrm{C}$, then decreased between $60-70{ }^{\circ} \mathrm{C}$ [5]. Likewise, Wang et al. [24] found a slight increase in, TPC between $30-50{ }^{\circ} \mathrm{C}$, followed by a slight decrease between $50-80{ }^{\circ} \mathrm{C}$, when using ultrasound-negative pressure cavitation extraction of blueberry leaves for $15 \mathrm{~min}$. In Kaderides et al. [31] study with USAE of pomegranate peels for $5 \mathrm{~min}$, TPC increased between $25{ }^{\circ} \mathrm{C}$ and $35^{\circ} \mathrm{C}$, then declined between $35^{\circ} \mathrm{C}$ and $45^{\circ} \mathrm{C}$. With maceration of S. officinalis leaves 
in $50 \%$ ethanol for $30 \mathrm{~min}$ to $90 \mathrm{~min}$, decreased, TPC was reported between $60{ }^{\circ} \mathrm{C}$ and $90{ }^{\circ} \mathrm{C}$. [32]. Thus, available evidence indicates that optimal USAE temperature needs to be adapted to the plant material and phenolic fractions of interest. Other extraction parameters (e.g., sonication time and $\mathrm{pH}$ ) also ought to be considered.

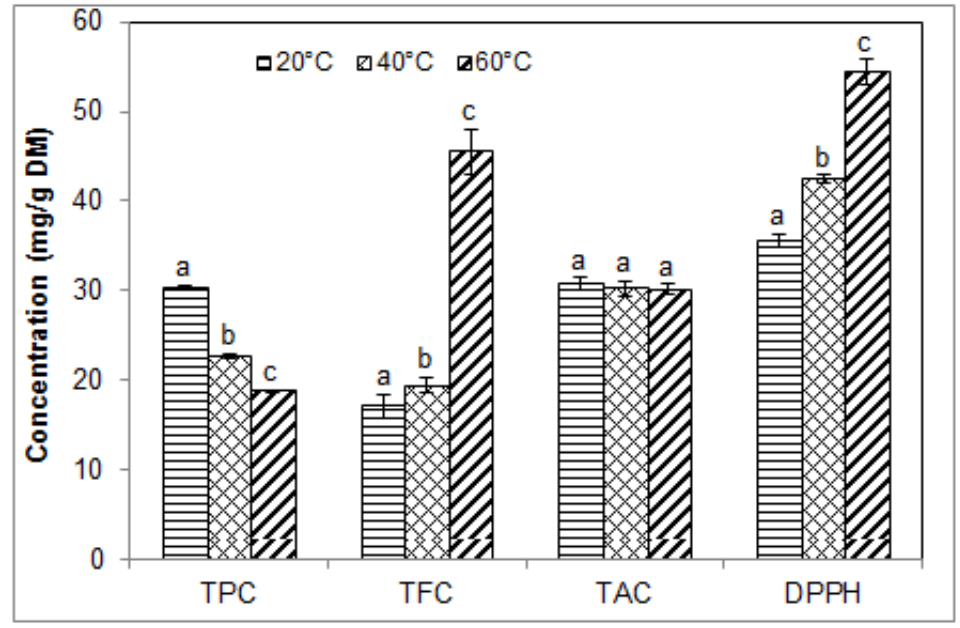

Figure 5. Effect of temperature on the phenolic contents and antioxidant activity of blueberry pomace ethanolic extracts from ultrasound assisted-extraction ( $50 \%$ ethanol, $40 \mathrm{~min}$ ). TPC, TFC, TAC: total phenolic, flavonoid and anthocyanin contents, respectively; DPPH, antioxidant activity by DPPH assay. Means ( $n=3$ replicates) \pm SD. Different letters indicate significant effect $(p \leq 0.05)$.

\subsection{Anthocyanin Profiles in Water Extracts and Ethanolic Extracts from Blueberry Pomace}

Anthocyanins, which are the glycosylated derivatives of anthocyanidins, are one of the main phenolic fractions present in blueberries. They are natural pigments responsible for the blue-purple coloration of the berries. The structures of common anthocyanins are illustrated in Figure 6.

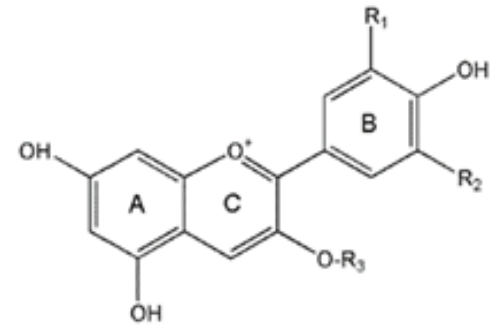

\begin{tabular}{|lccc|}
\hline & R1 & R2 & R3 \\
\hline Cyanidin & $\mathrm{OH}$ & $\mathrm{H}$ & sugar \\
\hline Delphini din & $\mathrm{OH}$ & $\mathrm{OH}$ & sugar \\
\hline Malvidin & $\mathrm{OCH}_{3}$ & $\mathrm{OCH}_{3}$ & sugar \\
\hline Pelargonidin & $\mathrm{H}$ & $\mathrm{H}$ & sugar \\
\hline Peonidin & $\mathrm{OCH}_{3}$ & $\mathrm{H}$ & sugar \\
\hline Petunidin & $\mathrm{OCH}_{3}$ & $\mathrm{OH}$ & sugar \\
\hline
\end{tabular}

Figure 6. Structures of select anthocyanins adapted from [38]. All were detected in the water extracts and ethanolic extracts of blueberry pomace, except pelargonidin and peonidin.

The elution order of anthocyanins depends on the polarity of the molecules, which is primarily affected by the anthocyanidin constituent, the number and type of attached sugar groups, as well as by any attached acyl groups $[39,40]$. Individual anthocyanins derived from the same anthocyanidins can have different elution orders if different sugar groups are attached [39]. Therefore, anthocyanin content and composition in the present study was determined following acid hydrolysis in order to convert the anthocyanins into anthocyanidins before identification and quantification by high-performance liquid chromatography with photodiode array detector (HPLC-PAD). Representative chromatograms are shown in Figure 7A,B for blueberry pomace water extracts and $50 \%$ ethanolic extracts, respectively. The USAE extraction conditions used to prepare these extracts were $40{ }^{\circ} \mathrm{C}-60 \mathrm{~min}, \mathrm{pH} 5.0$ and solid/liquid ratio $1 / 20$ in water, and $40{ }^{\circ} \mathrm{C}-40 \mathrm{~min}$, pH 6.3 and solid/liquid ratio 1/15 in 50\% ethanol, respectively. Chromatograms corresponding 
to commercial standards (delphinidin-cyanidin-pelargonidin-malvidin mixed and petunidin) are displayed in Figure 7C,D, respectively.
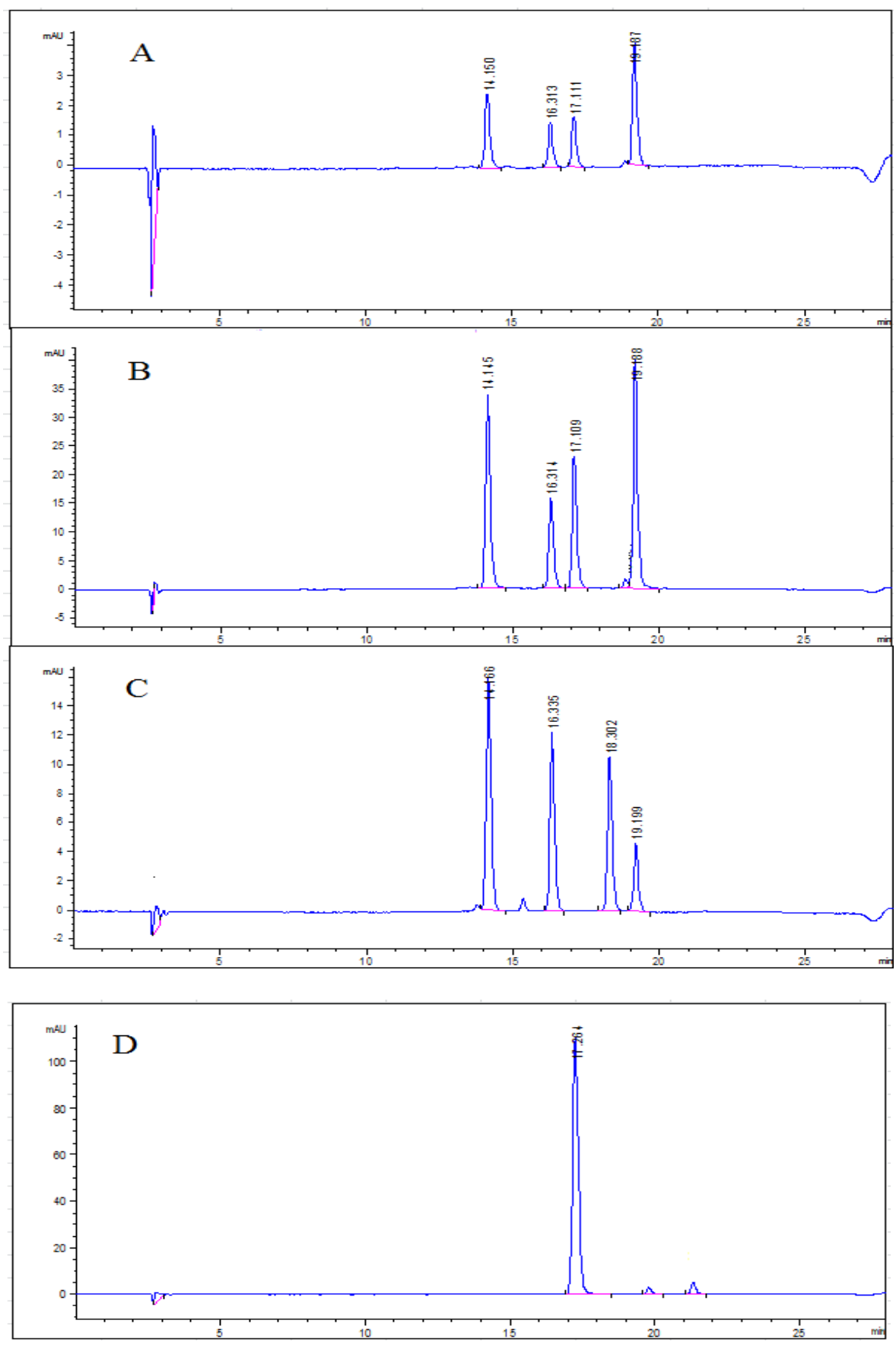

Figure 7. Representative high-performance liquid chromatography with photodiode array detector (HPLC-PAD) chromatograms of anthocyanidins in (A) blueberry pomace water extracts and (B) 50\% ethanolic extracts, and in preparations from commercial standards: (C) delphinidin-cyanidin-pelargonidin-malvidin and (D) petunidin. Approximate elution times: delphinidin $14.1 \mathrm{~min}$, cyanidin $16.3 \mathrm{~min}$, petunidin $17.1 \mathrm{~min}$, pelargonidin $18.3 \mathrm{~min}$, and malvidin $19.2 \mathrm{~min}$.

As can be seen in Figure 7A,B, four individual anthocyanidins were identified in the blueberry pomace extracts. Water extracts and ethanolic extracts showed similar anthocyanidin profiles qualitatively speaking. The four anthocyanidins were present in all the extracts obtained in this 
study, regardless of the USAE conditions investigated. They are delphinidin (elution time 14.15, 14.145 and $14.166 \mathrm{~min})$, cyanidin $(16.316,16.314$ and $16.335 \mathrm{~min})$, petunidin $(17.111,17.109$ and $17.264 \mathrm{~min})$ and malvidin (19.187, 19.188 and $19.199 \mathrm{~min})$, with elution times in water extracts, ethanolic extracts and standards, respectively. Anthocyanidins follow this elution series (from shortest to longest elution times) because of differences in the hydroxyl and methoxy substituents (R1 and R2 groups, Figure 6) attached to the anthocyanidins. Delphinidin has the highest polarity because it contains the most hydroxyl groups, thus eluting first, while malvidin has the most methoxy groups, giving it a more hydrophobic character and making it the last to elute from a reverse phase column [40].

Malvidin was the most abundant anthocyanidin in both the water and ethanolic extracts, followed by dephinidin, petunidin and cyanidin. These four compounds have been previously detected in blueberries [5,38-41], but some authors also found peonidin in addition to the four other anthocyanins [38-41]. In the present study, peonidin was not detected and the four anthocyanins identified are in agreement with those extracted and identified by $\mathrm{He}$ et al. [5] from blueberry wine pomace subjected to USAE. With the exception of peonidin, the relative abundances of individual anthocyanins in our work is consistent with the proportions reported by $\mathrm{Li}$ et al. [38] in different blueberries cultivars produced in China, specifically, malvidin $(41.0 \%)$, delphinidin $(33.1 \%)$, petunidin (17.3\%), cyanidin (7.1\%) and peonidin (1.35\%) [38]. In contrast, Wang et al. [41] found that cyanidin was the most abundant anthocyanin in different blueberry varieties, followed by peonidin, malvidin, delphinidin and petunidin. These variations in blueberry anthocyanin composition may be due to different blueberry varieties, agricultural practices, growing conditions, extraction conditions as well as analytical methods. Barnes et al. advised particular caution when identifying individual anthocyanins due to their high degree of structural complexity and similarity. Possible degradation of some anthocyanins when strong acids are used may also hamper their identification [40].

\section{Materials and Methods}

\subsection{Plant Material and Chemicals}

Blueberry pomace powder prepared by freeze-drying blueberry wine pomace (from Vaccinium angustifolium, lowbush blueberry) was kindly provided by Nova Agri Inc. (Centreville, NS, Canada) and stored at $-30{ }^{\circ} \mathrm{C}$ prior to use. All the chemicals were of analytical reagent grade. Sodium benzoate and hydrochloric acid were obtained from Sigma Scientific (Oakville, ON, Canada). Ethanol, methanol and formic acid of HPLC grade were purchased from Caledon Laboratories (Georgetown, ON, Canada). Folin-Ciocalteu's phenol reagent $(2 \mathrm{~N})$, sodium carbonate, sodium nitrite, aluminium chloride, gallic acid (GA), 6-hydroxy-2,5,7,8-tetramethylchroman-2-carboxylic acid (Trolox), and 2,2-diphenyl-1-picrylhydrazyl (DPPH) were purchased from Sigma-Aldrich Chemical Company (St Louis, MO, USA). (+)-Catechin and Folin-Ciocalteu reagent were purchased from Fluka (Milwaukee, WI, USA). Anthocyanin standards in the form of anthocyanidins (cyanidin chloride, dephinidin chloride, malvidin chloride, pelargonidin chloride, peonidin chloride and petunidin chloride) and dimethyl sulfoxide were obtained from Indofine Chemical Company Inc. (Somerville, NJ, USA).

\subsection{Ultrasound-Assisted Extraction (USAE)}

Ultrasound-assisted extraction was performed in an ultrasonic cleaner bath $(15.5 \times 14 \times 9 \mathrm{~mm}$, Symphony 97043-932, VWR, Mississauga, ON, Canada) with a maximum operating power of $35 \mathrm{kHz}$ and $64 \mathrm{~W}$. Prior to USAE, a beaker half-filled with distilled water was heated to the desired extraction temperature with stirring, using an agitator hotplate equipped with a temperature probe (IKA RCT basic, Staufen, Germany, 0-1500 rpm, 0-350 ${ }^{\circ} \mathrm{C}$ ) and the temperature was kept constant. Meanwhile, $2 \mathrm{~g}$ of blueberry pomace powder was poured into a $125 \mathrm{~mL}$ brown-coloured flask. Then, milliQ water or various ethanol-milliQ water ratios was added as the extraction solvent to reach the appropriate solid/liquid ratio and shaken for a few minutes. The flask was tightly closed to avoid solvent 
evaporation, then immersed by suspension into the beaker of distilled water for a few minutes so that the mixture reached the desired extraction temperature. The heated water was subsequently poured into the ultrasound bath and the flask with a weight ring was placed into the bath. USAE was carried out at maximum operating power $(35 \mathrm{kHz})$ for a specified duration at the set temperature (Table 1$)$. The treatment was conducted in batch mode without agitation and cooling system since preliminary experiments using distilled water without any materiel immersed showed no increase in temperature (data not shown). After extraction, the resulting extracts were centrifuged at $6000 \mathrm{rpm}$ for $15 \mathrm{~min}$ at room temperature and filtered by vacuum filtration through a $45 \mu \mathrm{m}$ Millipore polyvinylidene difluoride (PVDF) membrane. The filtrate was transferred into a $100 \mathrm{~mL}$ amber glass volumetric flask, wrapped with aluminium foil to prevent degradation of bioactive compounds, and concentrated by rotary evaporation under vacuum (Büchi Rotavapor RII, Rose Scientific Ltd., Essen, Germany) at $40{ }^{\circ} \mathrm{C}$ and 100 mbars for $20 \mathrm{~min}$. The filtered extract was stored in a brown-coloured bottle at $4{ }^{\circ} \mathrm{C}$ until further analyses. The USAE parameters that were varied are sonication time, solid/liquid ratio and solvent composition (\% ethanol in water), $\mathrm{pH}$ and temperature, according to the experimental scheme summarized in Table 1. All extractions were carried out in triplicate.

\subsection{Chemicals Analyses of Extracts}

All chemical analyses, except TAC which was determined by HPLC, were performed in a 96-well microplate reader Synergy 2 equipped with Gen5TM data analysis software (Biotek Instruments Inc., Winooski, VT, USA).

\subsubsection{Determination of Total Phenolic Content (TPC)}

Total phenolic content of the blueberry pomace extracts was determined using the method of Folin-Ciocalteu following the procedure described by Tournour et al. [42] with slight modification. Briefly, $25 \mu \mathrm{L}$ of either sample or standard properly diluted with milliQ water were transferred into appropriate wells. With a multichannel pipet, $125 \mu \mathrm{L}$ of $0.2 \mathrm{~N}$ Folin-Ciocalteu's reagent were added to each well, then the plate was swirled and incubated in the dark at room temperature. After 8 to $10 \mathrm{~min}, 125 \mu \mathrm{L}$ of $7.5 \%$ sodium carbonate was added. The obtained solution was mixed thoroughly and incubated at room temperature for $30 \mathrm{~min}$ at least and no more than $60 \mathrm{~min}$. Subsequently, the absorbance was recorded at $765 \mathrm{~nm}$ with a spectrophotometric microplate reader (Synergy HT Multi-Detection Microplate Reader, BioTek Instruments, Winooski, VT, USA). Absorbance was compared to a gallic acid standard curve $\left(\mathrm{R}^{2}=0.999\right)$ to quantify, TPC in the sample. The results were expressed as milligrams of gallic acid equivalents per gram of dry matter (mg GAE/g DM). Each standard and sample solution was analysed in triplicate.

\subsubsection{Determination of Total Flavonoid Content (TFC)}

Total flavonoid content (TFC) of the extracts was determined according to the 96-well microplate method [43] with some modification. A volume of $110 \mu \mathrm{L}$ of $0.066 \mathrm{M}$ sodium nitrite $\left(\mathrm{NaNO}_{2}\right)$ was added to each of the 96 wells and $25 \mu \mathrm{L}$ of standard or properly diluted sample solution was added. The plate was gently swirled and incubated at room temperature for $5 \mathrm{~min}$. Then, $15 \mu \mathrm{L}$ of $0.75 \mathrm{M}$ aluminium chloride $\left(\mathrm{AlCl}_{3}\right)$ solution was added to the mixture simultaneously in each of the wells using a multichannel pipet. The plate was swirled again and incubated at room temperature. After 6 min, $100 \mu \mathrm{L}$ of $0.5 \mathrm{M} \mathrm{NaOH}$ were added. The precipitations formed were gently dissolved using the multichannel pipet by avoiding the generation of air bubbles. Finally, absorbance was measured at $510 \mathrm{~nm}$ in the plate reader. All samples and standards were prepared in methanol and measured against a methanol reagent blank using the template of the microplate. Catechin $(15-500 \mu \mathrm{g} / \mathrm{mL})$ was used as a standard to generate a linear calibration curve $\left(R^{2}=0.998\right)$ and results were expressed as milligrams of catechin equivalents per gram of DM (mg CE/g DM). Each standard and sample solution was analysed in triplicate. 


\subsubsection{Determination of Total Anthocyanin Content (TAC) and Identification of Anthocyanins}

Total anthocyanin content (TAC) and individual anthocyanins were determined by HPLC-PAD using an Agilent 1100 series system equipped with a photodiode-array detector 200-800 nm (Agilent Technologies, Waldbronn, Germany). The column was a C-18 HPLC column, $5 \mu \mathrm{m}, 150 / 4.6 \mathrm{~mm}$ (YMC Inc., Wilmington, NC, USA). The elution solvents were (A) $10 \%$ formic acid/milliQ water $(v / v)$ and (B) $100 \%$ methanol. Solvent gradient was linear from $95 \% \mathrm{~A} / 5 \% \mathrm{~B}$ to $40 \% \mathrm{~A} / 60 \% \mathrm{~B}$ (0-20 min), isocratic at $40 \% \mathrm{~A} / 60 \% \mathrm{~B}(20-23 \mathrm{~min})$, linear from $40 \% \mathrm{~A} / 60 \% \mathrm{~B}$ to $95 \% \mathrm{~A} / 5 \% \mathrm{~B}(23-24 \mathrm{~min})$, and isocratic at $95 \% \mathrm{~A} / 5 \% \mathrm{~B}(24-28 \mathrm{~min}$, run time $28 \mathrm{~min})$. The detection wavelength was $520 \mathrm{~nm}$. Flow rate was $0.7 \mathrm{~mL} / \mathrm{min}$, column temperature $25^{\circ} \mathrm{C}$, pressure 300 bars, sample temperature was ambient and injection volume was $40 \mu \mathrm{L}$.

Commercially available anthocyanidin standards of cyanidin chloride, delphinidin chloride, malvidin chloride, pelargonidin chloride, peonidin chloride and petunidin chloride were separately dissolved in $2 \mathrm{~mL}$ of dimethyl sulfoxide (99.9\%) and used as standard stock solutions. The stock solutions were diluted in methanol $(v / v)$ to prepare $3.125,6.25,12.5,25.0$ and $50 \mu \mathrm{g} / \mathrm{mL}$ solutions for all standards. For identification of the anthocyanins present in the extracts, these six standard solutions were separately injected into the column.

TAC of the extracts were quantified after acid hydrolysis, which enables the determination of the aglycon forms of the anthocyanins (i.e., the anthocyanidins) (Figure 6). A $60 \mu \mathrm{L}$ sample was transferred into a $50 \mathrm{~mL}$ flat-bottom centrifuge tube and $3 \mathrm{~mL}$ of milliQ water were added. The tube was capped and the sample was vortexed for $60 \mathrm{~s}$. Then, $3.3 \mathrm{~mL}$ of hydrochloric acid $(\mathrm{HCl} 5 \mathrm{~N})$ were added. The mixture was heated in a water bath $\left(100^{\circ} \mathrm{C}\right.$ for $\left.60 \mathrm{~min}\right)$, then cooled to room temperature under running tap water. It was subsequently filtered through a $0.25 \mu \mathrm{m}$ PTFE membrane filter into an HPLC vial and analysed by HPLC-PAD. Two replicates per sample were prepared. Malvidin was used as a standard to generate a linear calibration curve $\left(R^{2}=0.997\right)$ and the results were expressed as milligrams of malvidin equivalents per gram of DM (mg ME/g DM). Standard and sample solutions were analysed in triplicate.

\subsubsection{Determination of Antioxidant Activity}

Antioxidant activity of the extracts was evaluated as DPPH free radical scavenging activity determined using the DPPH assay, as described by Herald et al. [43] with some modification. The DPPH stock solution $(350 \mathrm{mM})$ was prepared daily in methanol and used to prepare the working solution $(350 \mu \mathrm{M})$. Volumes of $225 \mu \mathrm{L}$ methanol, $25 \mu \mathrm{L}$ of methanol plus $200 \mu \mathrm{L}$ of DPPH working solution, and $25 \mu \mathrm{L}$ of standards or sample plus $200 \mu \mathrm{L}$ of DPPH were respectively added to blank wells, control wells, and standard or sample wells using a multichannel pipet. The plate was sealed with sealing tape, gently swirled then incubated for $6 \mathrm{~h}$ at room temperature in the dark. After incubation, absorbance was recorded at $517 \mathrm{~nm}$ using the above-mentioned microplate reader. The percentage of DPPH quenched was calculated using Equation. 1:

$$
\% \text { DPPH quenched }=\left[1-\left(\mathrm{A}_{\text {sample }}-\mathrm{A}_{\text {blank }}\right) /\left(\mathrm{A}_{\text {control }}-\mathrm{A}_{\text {blank }}\right)\right] \times 100
$$

where A is the absorbance of the sample, blank or control. Trolox $(62.5-1000 \mu \mathrm{M})$ was used as a standard to generate a calibration curve $\left(R^{2}=0.998\right)$ and DPPH free radical scavenging activity was expressed as trolox equivalents (mg TE/g DM).

\subsection{Statistical Analyses}

Descriptive statistics were calculated and expressed as means \pm standard deviation (SD). After checking for normality, means were compared using either one-way analysis of variance (ANOVA) followed by Tukey's multiple comparison test, or the Kruskal-Wallis test followed by the Dunn's multiple comparison test, as appropriate. Analyses were performed using Statistica version 7. Statistical significance was established at $p \leq 0.05$. 


\section{Conclusions}

The present study showed that the efficiency of ultrasound-assisted extraction of phenolic compounds from blueberry pomace is significantly influenced by the proportion of ethanol in the aqueous solvent, solid/solvent ratio, extraction temperature, sonication time and $\mathrm{pH}$. The antioxidant activity of the extracts was also significantly affected. A binary solvent system ( $50 \%$ ethanol/water) was more efficient for extracting total phenolics, flavonoids and anthocyanins from blueberry pomace. In addition, decreasing the solid/solvent ratio led to superior polyphenol contents and antioxidant activity of the extracts. With $50 \%$ ethanol, higher temperature increased the total flavonoid content and antioxidant activity, but lowered the total phenolic content. USAE under slightly basic $\mathrm{pH}$ conditions positively affected total phenolic content and antioxidant activity compared to acidic $\mathrm{pH}$, but lowered the anthocyanin content. Longer sonication time in water increased the anthocyanin content. The anthocyanin profiles of the ethanolic and aqueous extracts were qualitatively similar and consisted of malvidin, delphinidin, petunidin and cyanidin by decreasing order of relative concentration. These findings indicate that USAE is a method of choice for extracting high-value bioactive phenolics from blueberry pomace. For superior antioxidant activity of the extracts, the following USAE conditions are recommended: binary solvent system (50\% ethanol/water), low solid/ethanolic solvent ratio, slightly basic $\mathrm{pH}$ and temperature above $20^{\circ} \mathrm{C}$. Selective enrichment of different phenolic fractions is possible under select USAE conditions. These findings are helpful for the valorisation of blueberry pomace using USAE as a green technology to produce health-promoting phenolic compounds.

Author Contributions: Conceptualization, B.S.B.B., J.S., C.C.T., S.J.X.; Formal analyses, B.S.B.B.; Funding acquisition, B.S.B.B., C.C.T., J.S.; Investigation, B.S.B.B., S.J.X.; Methodology, B.S.B.B., J.S., C.C.T., S.J.X.; Project administration, J.S., C.C.T.; Resources: J.S., S.J.X.; Supervision, C.C.T., J.S.; Writing-original draft, B.S.B.B; Writing-review and editing, C.C.T., J.S., S.J.X., C.F.F., L.-T.L.

Funding: This research was funded by the Canadian Francophonie Scholarship Program (2017-4370), Agriculture and Agri-Food Canada (J-1344) and Université de Moncton (79357).

Acknowledgments: The authors thank Nancy Tregunno (Nova Agri Inc., Canada) for providing the blueberry pomace powder, as well as the Canadian Francophonie Scholarship Program for a postdoctoral fellowship to B.S.B.B., the A-Base research (J-1344) of Agriculture and Agri-Food Canada, and Université de Moncton for financial support to this research.

Conflicts of Interest: The authors have no conflict of interest to disclose. The funding sponsors had no role in the design of the study; in the collection, analyses, or interpretation of data; in the writing of the manuscript, and in the decision to publish the results.

\section{References}

1. Manach, C.; Scalbert, A.; Morand, C.; Rémésy, C.; Jiménez, L. Polyphenols: Food sources and bioavailability. Am. J. Clin. Nutr. 2004, 79, 727-747. [CrossRef] [PubMed]

2. Mudgal, V.; Madaan, N.; Mudgal, A.; Mishra, S. Dietary polyphenols and human health. Asian J. Biochem. 2010, 5, 154-162. [CrossRef]

3. Seeram, N.P. Berry fruits for cancer prevention, current status and future prospects. J. Agric. Food Chem. 2008, 56, 630-635. [CrossRef] [PubMed]

4. Reque, M.P.; Steffens, S.R.; da Silva, M.A.; Jablonski, A.; Flôres, H.S.; de Rios, O.A.; de Jong, V.E. Characterization of blueberry fruits (Vaccinium spp.) and derived products. Food Sci. Technol. Campinas. 2014, 34, 773-779. [CrossRef]

5. He, O.; Zhang, L.L.; Yue, X.Y.; Liang, J.; Jiang, J.; Gao, X.L.; Yue, P.X. Optimization of ultrasound-assisted extraction of phenolic compounds and anthocyanins from blueberry (Vaccinium ashei) wine pomace. Food Chem. 2016, 204, 70-76. [CrossRef] [PubMed]

6. Melo, S.P.; Massarioli, P.A.; Denny, C.; dos Santos, F.L.; Franchin, M.; Pereira, E.G.; Vieira, T.M.; Rosalen, L.P.; de Alencar, M.S. Winery by-products, extraction optimization, phenolic composition and cytotoxic evaluation to act as a new source of scavenging of reactive oxygen species. Food Chem. 2015, 181, 160-169. [CrossRef] [PubMed] 
7. Sójka, M.; Kołodziejczyk, K.; Milala, J. Polyphenolic and basic chemical composition of black chokeberry industrial by-products. Ind. Crop. Prod. 2013, 51, 77-78. [CrossRef]

8. Su, M.S.; Silva, L.J. Antioxidant activity, anthocyanins, and phenolics of rabbiteye blueberry (Vaccinium ashei) by-products as affected by fermentation. Food Chem. 2006, 97, 447-451. [CrossRef]

9. Klavins, L.; Kviesisa, J.; Nakurteb, I.; Klavins, M. Berry press residues as a valuable source of polyphenolics, extraction optimisation and analysis. Food Sci. Technol. 2018, 93, 583-591. [CrossRef]

10. Struck, S.; Plaza, M.; Turner, C.; Rohm, H. Berry pomace-A review of processing and chemical analysis of its polyphenols. Int. J. Food Sci. Technol. 2016, 51, 1305-1318. [CrossRef]

11. Statistic Canada. Estimates, Production and Farm Gate Value of Fresh and Processed Fruits. Available online: https: / / www150.statcan.gc.ca/t1/tbl1/en/tv.action?pid=3210036401 (accessed on 5 June 2018).

12. Da, S.R.; Rocha-Santos, T.A.P.; Duarte, A.C. Supercritical fluid extraction of bioactive compounds. TrAC Trends Anal. Chem. 2016, 76, 40-51.

13. Pandey, A.; Tripathi, S. Concept of standardization, extraction and pre phytochemical screening strategies for herbal drug. J. Pharmacogn. Phytochem. 2014, 2, 115-119.

14. Chemat, F.; Abert-Vian, M.; Cravotto, G. Green extraction of natural products, concept and principles. Int. J. Mol. Sci. 2012, 13, 8615-8627. [CrossRef] [PubMed]

15. Wang, L.; Weller, C.L. Recent advances in extraction of nutraceuticals from plants. Trends Food Sci. Technol. 2006, 17, 300-312. [CrossRef]

16. Castro-López, C.; Ventura-Sobrevilla, J.M.; González-Hernández, M.D.; Rojas, R.; Ascacio-Valdés, J.A.; Aguilar, C.N.; Martínez-Ávila, G.C.G. Impact of extraction techniques on antioxidant capacities and phytochemical composition of polyphenol-rich extracts. Food Chem. 2017, 237, 1139-1148. [CrossRef] [PubMed]

17. Bendicho, C.; De La Calle, I.; Pena, F.; Costas, M.; Cabaleiro, N.; Lavilla, I. Ultrasound-assisted pretreatment of solid samples in the context of green analytical chemistry. Trends Anal. Chem. 2012, 31, 50-60. [CrossRef]

18. Armenta, S.; Garrigues, S.; De Guardia, M. The role of green extraction techniques in Green Analytical Chemistry. Trends Anal. Chem. 2015, 71, 2-8. [CrossRef]

19. Esclapez, M.D.; Garčra-Pérez, J.V.; Mulet, A.; Cárcel, J.A. Ultrasound-assisted extraction of natural products. Food Eng. Rev. 2011, 3, 108-120. [CrossRef]

20. Chemat, F.; Rombaut, N.; Sicaire, A.G.; Meullemiestre, A.; Fabiano-Tixier, A.S.; Abert-Vian, M. Ultrasound assisted extraction of food and natural products. Mechanisms, techniques, combinations, protocols and applications. A review. Ultrason. Sonochem. 2017, 34, 540-560. [CrossRef] [PubMed]

21. Abad, R.B.; Bou-Maroun, E.; Reparet, J.M.; Blanquet, J.; Cayot, N. Impact of lipid extraction on the dearomatisation of an Eisenia foetida protein powder. Food Chem. 2010, 119, 459-466.

22. Galvan d'Alessandro Kriaa, K.; Nikov, I.; Dimitrov, K. Ultrasound assisted extraction of polyphenols from black chokeberry. Sep. Purif. Technol. 2012, 93, 42-47. [CrossRef]

23. Do, Q.D.; Angkawijaya, A.E.; Tran-Nguyen, P.L.; Huynh, L.H.; Soetaredjo, F.E.; Ismadji, S.; Ju, Y.H. Effect of extraction solvent on total phenol content, total flavonoid content, and antioxidant activity of Limnophila aromatica. J. Food Drug Anal. 2014, 22, 296-302. [CrossRef] [PubMed]

24. Wang, T.; Guo, N.; Wang, S.X.; Kou, P.; Zhao, C.J.; Fu, Y.J. Ultrasound-negative pressure cavitation extraction of phenolic compounds from blueberry leaves and evaluation of its DPPH radical scavenging activity. Food Bioprod. Process. 2018, 108, 69-80. [CrossRef]

25. Ćujić, N.; Šavikin, K.; Jankovic, T.; Pljevljakušić, D.; Zdunić, G.; Ibric, S. Optimization of polyphenols extraction from dried chokeberry using maceration as traditional technique. Food Chem. 2016, 194, 135-142. [CrossRef] [PubMed]

26. Lapornik, B.; Prošek, M.; Wondra, G.A. Comparison of extracts prepared from plant by-products using different solvents and extraction time. J. Food Eng. 2005, 71, 214-222. [CrossRef]

27. Xu, D.P.; Zheng, J.; Zhou, Y.; Li, Y.; Li, S.; Li, H.B. Ultrasound-assisted extraction of natural antioxidants from the flower of Limonium sinuatum: Optimization and comparison with conventional methods. Food Chem. 2017, 217, 552-559. [CrossRef] [PubMed]

28. Yang, L.; Cao, Y.L.; Jiang, J.G.; Lin, Q.S.; Chen, J.; Zhu, L. Response surface optimization of ultrasound-assisted flavonoids extraction from the flower of Citrus aurantium L. var. amara Engl. J. Sep. Sci. 2010, 33, 1349-1355. [PubMed] 
29. Safdar, M.N.; Kausar, T.; Jabbar, S.; Mumtaz, A.; Ahad, K.; Saddozai, A.A. Extraction and quantification of polyphenols from kinnow (Citrus reticulate L.) peel using ultrasound and maceration techniques. J. Food Drug Anal. 2017, 25, 488-500. [CrossRef] [PubMed]

30. Złotek, U.; Mikulska, S.; Nagajek, M.; Swieca, M. The effect of different solvents and number of extraction steps on the polyphenol content and antioxidant capacity of basil leaves (Ocimum basilicum L.) extracts. Saudi J. Biol. Sci. 2016, 23, 628-633. [CrossRef] [PubMed]

31. Kaderides, K.; Goula, A.M.; Adamopoulos, K.G. A process for turning pomegranate peels into a valuable food ingredient using ultrasound-assisted extraction and encapsulation. Innov. Food Sci. Emerg. Technol. 2015, 31, 204-215. [CrossRef]

32. Dent, M.; Dragović-Uzelac, V.; Penić, M.; Brnčić, M.; Bosiljkov, T.; Levaj, B. The effect of extraction solvents, temperature and time on the composition and mass fraction of polyphenols in Dalmatian wild sage (Salvia officinalis L.) extracts. Food Technol. Biotechnol. 2013, 51, 84-91.

33. Librán, C.M.; Mayor, L.; Garcia-Castello, E.M.; Vidal-Brotons, D. Polyphenol extraction from grape wastes, solvent and pH effect. Agric. Sci. 2013, 4, 56-62.

34. Cheng, A.; Chen, X.; Wang, W.; Gong, Z.; Liu, L. Contents of extractable and non-extractable polyphenols in the leaves of blueberry. Czech J. Food Sci. 2013, 31, 275-282. [CrossRef]

35. Kalt, W.; McDonald, J.E.; Donner, H. Anthocyanins, phenolics, and antioxidant capacity of processed lowbush blueberry products. J. Food Sci. 2000, 65, 390-393. [CrossRef]

36. Ruenroengklin, N.; Zhong, J.; Duan, X.; Yang, B.; Li, J.; Jiang, Y. Effects of various temperatures and pH values on the extraction yield of phenolics from litchi fruit pericarp tissue and the antioxidant activity of the extracted anthocyanins. Int. J. Mol. Sci. 2008, 9, 1333-1341. [CrossRef] [PubMed]

37. Amendola, D.; De Faveri, D.M.; Spigno, G. Grape marc phenolics, extraction kinetics, quality and stability of extracts. J. Food Eng. 2010, 97, 384-392. [CrossRef]

38. Li, D.; Meng, X.; Li, B. Profiling of anthocyanins from blueberries produced in China using HPLC-DAD-MS and exploratory analysis by principal component analysis. J. Food Compos. Anal. 2016, 47, 1-7. [CrossRef]

39. You, Q.; Wang, B.; Chen, F.; Huang, Z.; Wang, X.; Luo, P.G. Comparison of anthocyanins and phenolics in organically and conventionally grown blueberries in selected cultivars. Food Chem. 2011, 125, 201-208. [CrossRef]

40. Barnes, J.S.; Nguyen, H.P.; Shen, S.; Schug, K.A. General method for extraction of blueberry anthocyanins and identification using high performance liquid chromatography-electrospray ionization-ion trap-time of flight-mass spectrometry. J. Chromatogr. A 2009, 1216, 4728-4735. [CrossRef] [PubMed]

41. Wang, H.; Guo, X.; Hu, X.; Li, T.; Fu, X.; Liu, R.H. Comparison of phytochemical profiles, antioxidant and cellular antioxidant activities of different varieties of blueberry (Vaccinium spp.). Food Chem. 2017, 217, 773-781. [CrossRef] [PubMed]

42. Tournour, H.H.; Marcela, S.A.; Magalhaes, L.M.; Barreiros, L.; Queiroz, J.; Cunha, L.M. Valorization of grape pomace, extraction of bioactive phenolics with antioxidant properties. Ind. Crop. Prod. 2015, 74, 397-406. [CrossRef]

43. Herald, T.J.; Gadgil, P.; Tilley, M. High-throughput microplate assays for screening flavonoid content and DPPH-scavenging activity in sorghum bran and flour. J. Sci. Food Agric. 2012, 92, 2326-2331. [CrossRef] [PubMed]

Sample Availability: Standards of catechin, cyanidin, delphinidin, gallic acid, malvidin, pelargonidin, peonidin and petunidin are commercially available.

(c) 2018 by the authors. Licensee MDPI, Basel, Switzerland. This article is an open access article distributed under the terms and conditions of the Creative Commons Attribution (CC BY) license (http://creativecommons.org/licenses/by/4.0/). 